\title{
Virtual modelling for simulation-based lean education
}

\section{Elizabeth Cudney*, Steven M. Corns and Akalpit Gadre}

Department of Engineering Management and Systems Engineering, Missouri University of Science and Technology,

Rolla, Missouri 65401, USA

E-mail: cudney@mst.edu

E-mail: cornss@mst.edu

E-mail: akg7cd@mst.edu

*Corresponding author

\begin{abstract}
This research presents a virtual simulation to enable students to explore and learn lean concepts through virtual experimentation. Exposing students to these concepts is crucial as demand for engineers with an in-depth understanding of lean philosophies is rising. The virtual simulation platform developed provides students an environment to apply lean concepts in experiments in the same manner as current methods for teaching lean, which include hands-on projects and simulation. The platform provides a simple interface, the ability to store results, and the modelling power of state of the art virtual reality software. The virtual simulation platform is built using the VE-Suite virtual engineering framework, which provides user-friendly dialogue boxes, graphical models, performance display gauges, and an editable layout. A mathematical model of an industrial process where lean can be implemented was created for this framework. In addition, a survey instrument is planned to gather information about strengths and weaknesses of the method to implement continuous improvement to the model. By working through this virtual simulation, students can experience multiple applications of lean in a real world setting without constructing an entire line or disrupting production in an existing line.
\end{abstract}

Keywords: lean; education; simulation; modelling; virtual engineering.

Reference to this paper should be made as follows: Cudney, E., Corns, S.M. and Gadre, A. (2014) 'Virtual modelling for simulation-based lean education', Int. J. Lean Enterprise Research, Vol. 1, No. 1, pp.3-21.

Biographical notes: Elizabeth Cudney is an Assistant Professor in the Engineering Management and Systems Engineering Department at Missouri University of Science and Technology. She received her BS in Industrial Engineering from North Carolina State University, Master of Engineering in Mechanical Engineering and Master of Business Administration from the University of Hartford, and her Doctorate in Engineering Management from the University of Missouri, Rolla. In 2010, she was inducted into the ASQ International Academy for Quality. She received the 2008 ASQ A.V. Feigenbaum Medal and the 2006 SME Outstanding Young Manufacturing Engineering Award. She is an ASQ Certified Quality Engineer, Manager of Quality/Operational Excellence, and Certified Six Sigma Black Belt. She is a member of the ASEE, ASEM, ASME, ASQ, IIE, SAE, and the Japan Quality Engineering Society (JQES). 
Steven M. Corns received his $\mathrm{PhD}$ in Mechanical Engineering from Iowa State University in 2008. He is currently an Assistant Professor of Engineering Management and Systems Engineering at Missouri University of Science and Technology. He is also the Chief Engineer for Hybrid Power Company, LLC. His research interests are in the areas of evolutionary computation applications, the mechanics of information transfer in evolutionary algorithms, and model-based approaches for complex systems design and analysis.

Akalpit Gadre received his MS in Manufacturing Engineering from Missouri University of Science and Technology in 2011. He received his Bachelor of Engineering in Mechanical Engineering from The University of Pune, India in May 2010.

\section{Introduction}

Global competition and customer demands are driving industrial operations to adopt lean principles. Lean is used within industry to reduce cost by solving complex, ill-structured, real-world problems that require multiple facets of industrial knowledge. From its beginnings at the Toyota Corporation, lean manufacturing has aimed to reduce production costs through the elimination of wastes in operations (Cudney and Elrod, 2011). The success in implementing these principles has driven this adoption throughout the manufacturing industry and has since expanded to service and healthcare. This has created competition among the global corporations to 'go lean' and has increased the demand for engineers with an in-depth understanding of lean philosophies and implementation (Cudney et al., 2011). Current methods for teaching lean include hands-on projects, presentations, and guest lecturers. This lecture-based approach leaves engineering graduates less prepared for the engineering profession and does not effectively motivate students in the learning process, as they are passive recipients of the information (Dodd, 2008). To remedy this, this research incorporates virtual simulations to these existing methods of instruction. This research focuses on improving lean education by implementing virtual engineering simulation in lean and related courses (Cudney et al., 2011). This simulation approach for imparting education also adheres to the National Academy of Engineering's (NAE) recommendations (National Academy of Engineering, 2005). In this work, we present a virtual simulation platform that enables students to explore and learn lean concepts through a series of experiments. The creation of a mathematical model of a lean application to a process is described, followed by a discussion of how the virtual simulation platform was created. This virtual simulation platform can be used within a larger lean curriculum to provide a hands-on learning experience for students being introduced to lean.

A series of assignments were created for students to work through as a part of their lean engineering education. We present a method to assess the educational benefits of this virtual simulation platform to validate its suitability for classroom instruction through a paper-based case study. The assignments require the implementation of various lean tools, and are included as part of the case study. As the students work through these assignments, the feedback of the educators and the students will be collected. The students will be surveyed at the beginning of the semester to gain insight into their perceptions of the course. The students will also be surveyed regarding their experiences 
using the case study and the effectiveness of a simulation to gauge the effectiveness of the pedagogy and students' opinions of the hands-on approach. This information will be utilised to make relevant improvements in the virtual simulation to increase the retention and motivation of students.

This virtual simulation approach builds on current simulation methods, but also includes immersive virtual reality capabilities, which have been proposed as a method for improving how manufacturing tasks are taught (Sanders and Udoka, 2010). These capabilities include mock-ups of the shop floor that can be navigated and interacted with in much the same manner as an actual shop floor would be used. The virtual simulation environment can be accessed from many different types of computer systems ranging from a virtual reality theatre to a laptop computer, making it possible for students to use it at a variety of locations. As an open source distributed system, multiple students can freely download the tools and collaborate in one environment even from geographically separated locations, making it ideal for a distance education system.

The virtual simulation is intended to make the assignments more interesting, immersive, and learner friendly. This is accomplished through the VE-Suite framework (McCorkle and Bryden, 2008) to ensure that the design includes user-friendly dialogue boxes, graphical models of machines, performance display gauges, and an editable layout. For its operation, the virtual simulation platform uses laws of operations management such as Little's Law, economic order quantity (EOQ) models, and cycle time; and enables students to implement various lean concepts such as pull system, just-in-time (JIT), single piece flow, standard work, takt time, single minute exchange of dies (SMED), kaizen, kanban, and U-shaped layout by modifying the process parameters such as process times, setup times, layout, demand rate, and machine positions.

The simulation starts with a traditional push type mass production line consisting of four work stations and the students are expected to improve the line by implementing lean techniques. The assignments developed for the simulation include lean tools such as standardised work, heijunka, SMED, kaizen, takt time, and kanban. By working through these assignments, students experience the advantages of implementing lean tools and face the real life problems encountered while doing so.

In the case study, the students are presented with a hypothetical automotive axle manufacturing line that consists of four processes and is operated on the push type production system. The students are asked multiple questions guiding them through the application of various lean tools to the production line in the case study. By working through the questions students become acquainted with the process of applying lean tools. Solving the questions also exposes students to the continuous improvement philosophy, as each question calls for improvements in the process that are appropriate based on the previous question.

The focus of this paper is to investigate the use of virtual simulations to educate students on the use of lean tools related to the physical manipulations and observations used as a part of the manufacturing system. This method allows the students to perform experiments with lean in an immersive environment that matches the physical laboratory as closely as possible, making it feasible for a distance education program to use a hands-on approach when it is not feasible for the students to attend the lab in person. This can be used to replace a shop floor type simulation within a broader lean education program. 


\section{Review of lean}

The basic idea underlying the lean philosophy is to identify and reduce (preferably eliminate) the non-value adding (NVA) activities. Shigeo Shingo, one of the developers of Toyota production system (TPS), identifies seven major wastes in a system including (Liker, 2004):

1 Overproduction: producing more or earlier than required.

2 Transportation: movement of the raw material, work-in-process (WIP) inventory, and the finished goods throughout the manufacturing life cycle. WIP includes all the unfinished products in the production process which are waiting in queue for processing or are being stored in the warehouse from where they can be later retrieved for further processing.

3 Motion: changes in position performed by operators and movements of machines before, during, and after the process.

4 Waiting: time spent by the WIP waiting in queue for or in front of a machine and idle times for operators and machines.

5 Over processing: unnecessary processing and use of tools and equipment.

6 Inventory: accumulation of raw materials, WIP, and finished goods.

7 Defects: products to be reworked or scrapped.

Lean manufacturing aims to achieve low inventories, cellular manufacturing, quick setup, and process flexibility (Klier, 1993). Lean tools improve the company's operations. Value stream mapping (VSM) displays the existing process clearly. Flexible work system and $5 \mathrm{~S}$ help organise the factory. Standard work, SMED, total productive maintenance (TPM), and jidoka assist in the design and implementation of improved processes. JIT and heijunka connect the company to its suppliers and customers. Group technology, cellular manufacturing, synchronous manufacturing, focused factories, $5 \mathrm{~S}$, visual control systems, kanban, rapid replenishment, JIT supply, and JIT shipping reduce waiting time. Visual control systems, 5S, standard work, SMED, jidoka, and TPM reduce activity duration and cost. Jidoka and TPM also reduce the amount of material used. SMED, 5S, visibility in layout, and the ability to perform multiple functions result in substantial flexibility in production. Poka-yoke eliminates waste due to defects and process unreliability (Mukhopadhyay and Shanker, 2005; Pavnaskar et al., 2003; Rivera and Chen, 2007). JIT aims to synchronise the pace of the entire production system and produce at takt time (Deif, 2010).

Pavnaskar et al. (2003) classify lean manufacturing tools, provide guidance for the usage of these tools, and establish a connection among problems, wastes, and lean tools through various examples. Wang et al. (2009) survey lean tool implementation by various companies and conclude that companies typically start with the implementation of standardised work, 5S, kaizen, and kanban as these tools take less than five years to implement. The second stage is to implement 5S, poka-yoke, kaizen, JIT, and standardised work, which typically take five to ten years to implement. To gain the acceptance of management and operators, it is necessary to demonstrate proof of success of a new system (Mukhopadhyay and Shanker, 2005). Therefore, while applying lean 
tools in a company, it is necessary to go step-by-step, work on various projects, and integrate these projects into a plant-wide lean system.

\section{Review of literature}

Research has found that hands-on experience is more effective in educational settings than books, lectures, or video clips (Wang et al., 2009). Traditionally, it has been necessary to have physical laboratories for students to gain hands-on experience. However, full-scale experimentation in factory settings is not feasible due to the high development and maintenance expense (Dessouky et al., 2001). It is also difficult to allow students into an industry for experimentation. An alternative and effective way to achieve hands-on experience of production systems in an educational setting would be to create a simulated factory (virtual factory) or product line. Simulation has been proven to be a powerful tool to model and analyse processes (Wang et al., 2009). The simulation of virtual factories to enable students to experience the range of typical decisions that senior managers face daily is a part of the 'tell, show, and involve' methods (Wall and Ahmed, 2008).

Virtual factories are currently used within manufacturing to represent physical plants. The major benefit of a virtual factory lies in the ease of representing physical system components (i.e., equipment and materials) and conceptual system components (i.e., process plans and equipment schedules) and emulating their real-life counterparts. In a virtual factory the creation of a full-scale factory is not necessary as an abstract representation of equipment is sufficient.

The use of factory simulators has also been studied. Choi et al. (2004) propose and explain a virtual factory simulator. They validate it by comparing their simulator to a flexible manufacturing system. Moris et al. (2008) identify the need to focus on improvement of modelling features and estimation of distributions for production data. Yang et al. (2008) identify the need to integrate process simulation, evaluation platform, and management information systems. Bagchi and Retzo (2008) describe a discrete event simulator developed for daily prediction of WIP position in a wafer fabrication factory. Dengiz and Akbay (2000) demonstrate the use of simulation modelling approach for the design and optimisation of pull manufacturing system at a printed circuit board (PCB) manufacturing company. Ni et al. (2011) solve a WIP control system problem by simulating the production lines virtually to address the critical WIP level setting. Tobail et al. (2012) used agent-based modelling to create a web-based supply chain simulation game to expand on the use of simulators by applying the concept to learning supply chain management. While these approaches provide many benefits, only the web-based supply chain management simulator can be easily distributed to potential students freely. The tool proposed in this work provides users at any location with an immersive lean education experience usually found only in campus-based laboratories.

There is also research indicating how a model of lean production systems should be approached. Lee et al. (2011) state that as the production lines are complex it is necessary to choose/develop models or modelling techniques carefully. Moris et al. (2008) conclude that, while creating a computer simulation model, focus on the improvement of modelling features and accuracy in distribution for production data is necessary. Yang et al. (2008) identify the need to integrate process simulation, evaluation platform, and management 
information systems. Rezg et al. (2004) follow a five stage approach for the study of their simulation including

1 construction of a physical model that reflects the system requirements with the desired accuracy

2 formation of the rules for treatment of the products

3 description of the manufacturing progress of each product through the line

4 decision regarding the inventory control policy and the maintenance strategy

5 development of the production line scenarios and their optimisation.

A typical lean curriculum as it is taught at many universities consists of some informative lectures, a course project, and a paper presentation. Several attempts have been made to aid lean education by the usage of computer simulation. Wan et al. (2008) propose a web-based kanban system that uses a hypertext preprocessor (PHP) and a structured query language (MySQL) platform to make commonly used simulation games more effective at imparting knowledge. They also propose a fully web-based lean simulation game. Wan et al. further state that most widely implemented games in the classroom have some deficiencies in communication with the user. Therefore, innovative simulations with better graphical user interfaces are necessary to enhance lean education.

To verify the simulation models created, Madan et al. (2005) analysed the results of a single part followed throughout the system. They state that model verification should be performed while the simulation model is in the development stage. Lee et al. (2011) conclude that industrial-based test cases are essential to validate a simulation. Leye et al. (2009) give an overview of various methods and their relevance for model validation. Aumann (2007) presents a methodology for developing models and simulating complex systems. This methodology is based on four steps including

1 the process of planning and developing models

2 the document containing units and interrelationships of various concepts

3 the linkage between model design, implementation, and synthesis

4 the documentation of the validation and critique process.

This research takes a step further by developing a factory simulation addressing several lean tools for use in educational settings.

\section{Mathematical model}

In order to develop a simulation it is necessary to develop a mathematical model first (Vickovic et al., 2011). For the evaluation of lean tools, a mathematical model must include the factors that influence the process wastes, such as inventory and WIP. High levels of WIP result in increased cost of inventory, scrap, and hidden quality problems. Because of this, one focus of lean is to keep WIP to a minimum. The most important law governing WIP is Little's Law. Little's Law states that, "under steady state conditions, the average number of items in a queuing system (i.e., WIP) equals the average rate at which items arrive (i.e., throughput) multiplied by the average time that an item spends in 
the system (i.e., cycle time)" (Little and Graves, 2008). Little's Law is provided in equation (1).

$$
C T=W I P / T h
$$

This equation has been most extensively used to heuristically derive the various equations connecting the simulated production line described below.

$$
\begin{aligned}
& T_{p}=\left(\sum_{i=1}^{n} S_{i}+\sum_{i=1}^{n} P_{i}+\sum_{i=1}^{n} U_{i}+\sum_{i=1}^{n} T_{i}\right) \times S \times O E E \\
& W T=T_{p} \times(W I P-1) \\
& C T=T_{p}+W T \\
& T h b=D \times\left(1+\sum_{i=1}^{n} R r_{i}\right) \\
& T T=T_{a} / D \\
& O E E=\left(1 / \sum_{i=1}^{n} U T_{i}\right) \times\left(1+\sum_{i=1}^{n} R r_{i}\right) \times P_{e}
\end{aligned}
$$

where

$n \quad$ number of machines

$T_{p} \quad$ total time at the processes

$S_{i} \quad$ setup time at machine $i$

$P_{i} \quad$ process time at machine $i$

$U_{i} \quad$ unloading time at machine $i$

$T_{i} \quad$ transport time at machine $i$

$S \quad$ safety allowance

$U T_{i}$ cumulative uptime percentage (signifies availability efficiency)

$R r_{i} \quad$ rejection rate ratio (signifies quality efficiency)

$P_{e} \quad$ performance efficiency

$W T$ waiting time

WIP work in progress

$C T$ cycle time

Th throughput, the average number of items arriving per unit time

Thb throughput at bottleneck

$D$ demand rate 
TT takt time

$T_{a} \quad$ available time.

For simplification, it was assumed that the production line is operated by only one operator and only one process can run at a time. Equation (2) states that the total time is equal to the summation $\left(\sum_{i=1}^{n}\right)$ of the setup, process, unloading, and transportation times

at all stations, multiplied by a safety time factor and overall equipment effectiveness (OEE) of a manufacturing line. Equation (3) states that the waiting time is the product of the total time and number of products waiting in queue (here WIP is minus one as only one product can be worked on at a time). Equation (4) states that the cycle time is the addition of the total time and waiting time. Equation (5) limits the throughput rate at the bottleneck to the addition of demand and rejected products. Equation (6) (Nicholas and Soni, 2006) states that the takt time should be equal to the ratio of available time to the demand rate. Equation (7) (Braglia et al., 2009; Reyes et al., 2010) states that OEE is the product of availability efficiency, quality efficiency, and performance efficiency.

The mathematical model is also used to calculate the number of kanban cards [equation (8)] (Mukhopadhyay and Shanker, 2005). The number of kanban cards depends on the order package, which includes information such as the demand rate, available time, and safety time. The container size depends upon the size and process constraints for the product.

$$
n=\frac{D \times\left(T_{a}+S_{f}\right)}{N}
$$

where

$n \quad$ number of kanban cards

$D$ demand rate or number of orders rate

$T_{a}$ manufacturing lead time or time available

$S_{f}$ safety time

$N$ container size.

These concepts give the student a broad understanding of how lean is implemented. These equations were validated using Matlab and data from an actual production line. The validation program was designed to get input data from an excel sheet and calculate total time, cycle time, takt time, throughput, and total rejection rate as output. These equations were coded into the $\mathrm{C}++$ language for integration into a virtual model to allow user interaction with the variables described in the mathematical model.

\section{Virtual model}

Yang et al. (2008) recommend that a factory model should provide a platform to verify, simulate, analyse, and optimise production processes. It should also incorporate both the geometrical as well as manufacturing properties of the equipment in a model. 
Geometrical properties are the size, shape, and weight of the machine; while manufacturing properties are machine size, job size, and capacity. Further, a production system has four facets; namely, the product, the process, production planning, and manufacturing resource planning. A simulation model should encompass the four facets and their relations, and iterate through the production system model repeatedly. To meet these expectations, this research adhered to the model building procedure explained in the subsequent paragraphs.

The first step in creating the virtual simulation platform for lean was to create a layout that could be changed according to the user. VE-Suite (McCorkle and Bryden, 2008) was used in this research for the simulation. VE-Suite is a virtual simulation software framework that combines several open source libraries such as open screen graph and VRJuggler to create virtual environments. In addition, the framework allows for the introduction of other software tools to make it possible for the user to create animations and designate physical properties such as mass and friction to the models. This allows for an integrated simulation environment for the evaluation of system processes (Kande and Corns, 2011). First, 3D visualisation models of the machines used in this simulation were created using Blender, an open source 3D modelling package. The blender files were then converted to a format compatible with VE-Suite and imported to VE-Xplorer (VE-Suite's graphical engine) to arrange the layout (Figure 1), and the models were then assigned physical properties.

Figure 1 Layout in VE-suite (see online version for colours)

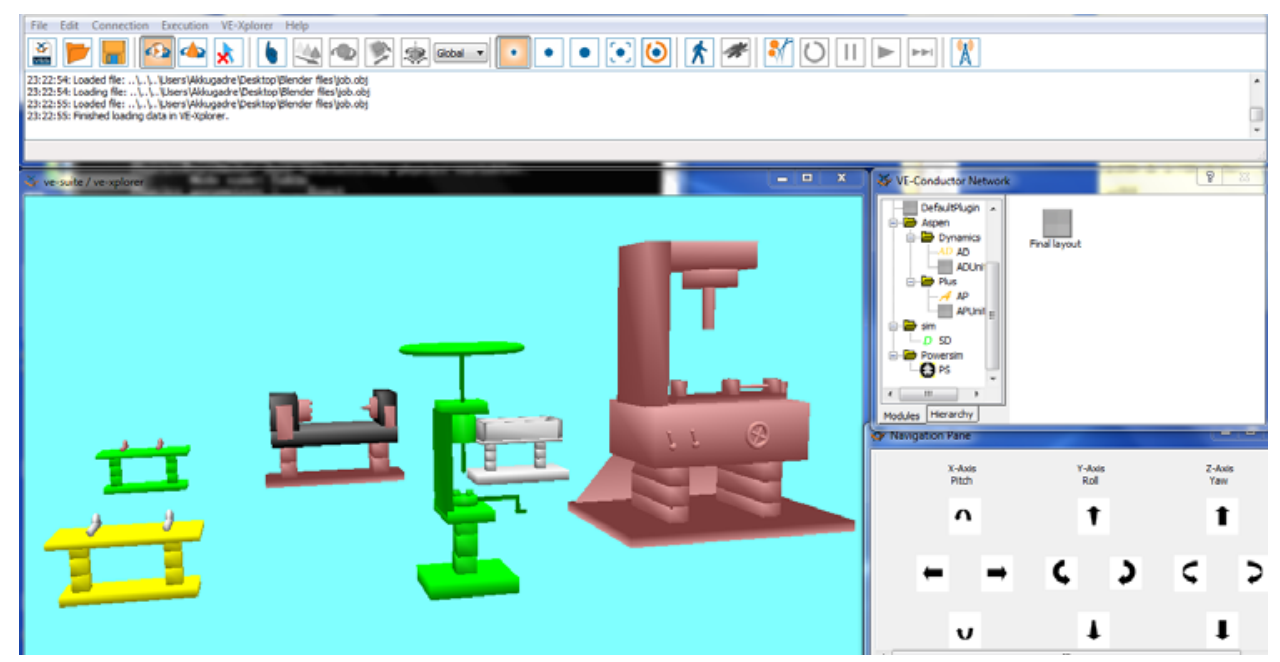

The equations used to mathematically link the machines into a production line developed in the preceding section were created for addition to the framework. The graphical user interface for the virtual simulation was created using the WX widgets' Anthemion Dialog Blocks 4.39. User interface 2 (Figure 2) accepts user input from the time study conducted on the simulated process. User interface 3 (Figure 3) accepts user input regarding the fatigue factor and job orders. It also displays the output in the form of process performance indicators. These are governed by various equations discussed in the previous section. 
Figure 2 User interface to enter time study data

\begin{tabular}{l}
\hline Times \machine \# \\
Enter distance from privious \\
Enter setup time \\
Enter process time \\
Enter uploading time \\
Enter transportation time \\
Enter Machine up time \\
Enter machnine rejection rate
\end{tabular}

Figure 3 User interface to enter input parameters and get output parameters

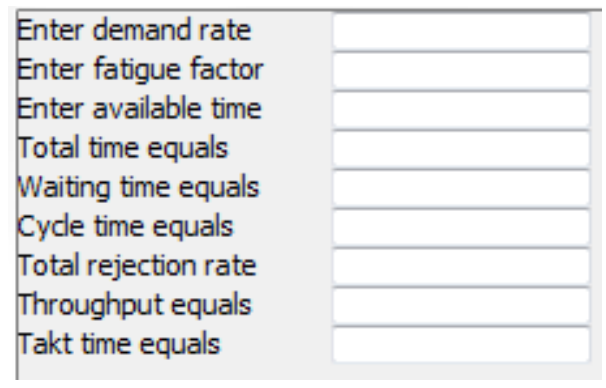

The model, code, and user interface were then integrated and the graphical plug-in for VE-Suite was developed to connect communication between these elements, allowing the user to solve the equations describing the manufacturing process. This makes it possible for the user to enter the production data such as WIP, demand rate, available time, and throughput to obtain output such as cycle time, total rejection rate, waiting time, and other production parameters.

The second validation was the testing of the virtual simulation. This was performed by entering the same information used in the first validation step and checking the solutions against each other. The results matched both the first validation and the field data from which the mathematical model was developed. The simulation model only focuses on the lean tools that require mathematical calculations and lacks the philosophical aspect of lean, so the final validation is the evaluation of subject matter experts to ensure that the practices recommended match what is implemented in practice. In addition, other tools should be developed to aid the simulation for designing a better assignment for lean and related courses.

\section{Virtual model assignments}

Several assignments were included in the model to bolster students' learning and to allow for the final validation of the simulation. Remembering that one of the seven most important wastes of production is inventory or level of WIP, with higher inventory resulting in increased cost, scrap, and hidden quality problems. Because of this, the focus of the student assignments is to keep WIP to a minimum. The first assignment focuses on the calculation of cycle time using Little's Law (Figure 4). Students enter the values of 
WIP and throughput by observing the time and process study data that determines the cycle time.

Figure 4 User interface for Little's Law (see online version for colours)

\begin{tabular}{|c|c|c|}
\hline Pl. enter the WIP & Pl. enter the Throuc & Calculate CT \\
\hline
\end{tabular}

The second assignment is the application of heijunka or demand and production levelling (Figure 5). Students are given three options. The first option has a demand of 50 pieces every month with the minimum deviation of two pieces. In order to achieve this, the company has to pay a discount of $10 \%$ on the selling price (SP). The second option has demand of 50 pieces with a deviation of seven pieces, and the company has to pay a discount of $5 \%$ on the SP. The third plan has demand of 45 pieces with a deviation of 15 pieces, and the company does not have to pay a discount. Students would select a plan and enter the demand rate (i.e., number of orders) in other assignments. As the students apply JIT, they will realise that selecting the option with the least demand variation is the better solution.

Figure 5 User interface for heijunka assignment

\begin{tabular}{|cccc|}
\multicolumn{5}{c}{ Select one of the following contracts } \\
Contract No. & Mean Demand & Standard Deviation & Discount Given \\
1 & 50 pcs & 20 pcs & $10 \%$ \\
2 & 50 pcs & 7 pcs & $5 \%$ \\
3 & 45 pcs & 15 pcs & $0 \%$
\end{tabular}

Figure 6 User interface for SMED assignment

\begin{tabular}{|l|l|}
\hline \multicolumn{2}{|c|}{ Apply SMED to the setup operation of clamping a job to chuck } \\
\hline Task discription \\
\hline Enter 1st task \\
\hline Enter 2nd task \\
\hline Enter 3rd task \\
\hline Enter 4th task \\
\hline Enter 5th task \\
\hline Enter 6th task \\
Total internal setup time after changes $=$ \\
\hline
\end{tabular}

The third assignment is to implement SMED (Figure 6). SMED refers to a quick changeover of setup from manufacturing one part to the next part (Liker, 2004). This is implemented by allowing the students to reduce the setup time for a process by implementing SMED. In this assignment students are expected to differentiate the internal setup (setup that must be performed on the machine while it is idle) and the external setup (setup that can be performed outside the machine while the machine is 
running), change the internal setup to external setup, and change the setup time in the model.

The fourth assignment is to calculate the number of kanban cards [Figure 7 and equation (8)]. Students select an order package and enter the relevant demand rate and available time. Safety time is obtained from time study data and the container size depends upon the size and process constraints for the product.

Figure 7 User interface for number of kanban cards assignment

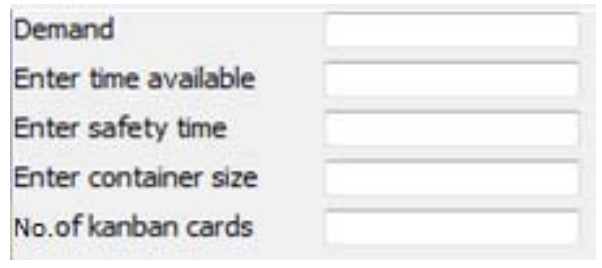

The fifth assignment is to calculate the takt time (Figure 8). Takt time is the ratio of total available time to total number of products in the order, which can be thought of as the time interval at the end of which one product should be produced to meet customer demand. In general, the cycle time of a process should not exceed the takt time (Nicholas and Soni, 2006). The assignment includes calculating takt time and comparing it with cycle time to determine if the current process can meet customer demand.

Figure 8 User interface for takt time assignment (see online version for colours)

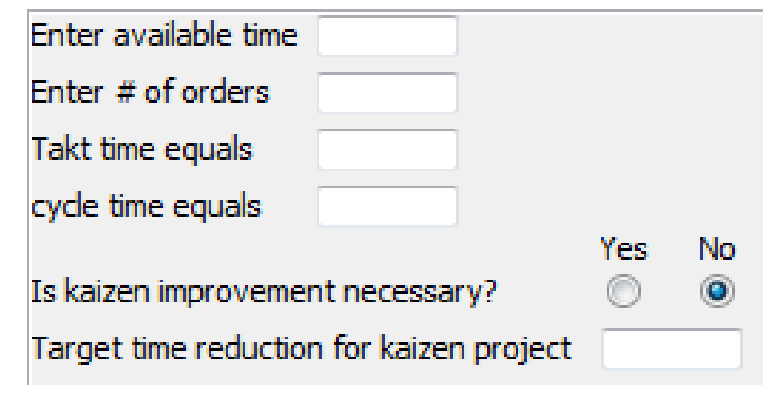

The work performed on this research up to this point has included the creation of the mathematical model, development of various assignments, 3D models, layout, and code for the simulation in VE-Suite. While the model is representative of a manufacturing line, an evaluation of the ability of students to implement the models is the final validation.

\section{Case study}

To achieve the maximum benefit from mathematical model and the simulation, the two components should be experimentally validated and a sufficient number of experiments must be conducted to gain statistical significance. Validation is a long process and consumes more than $50 \%$ of the modelling time (Aumann, 2007). Therefore, to ensure the accuracy and effectiveness of the final validation it will be incorporated into a 
classroom environment to gather data from multiple iterations. In order to validate the mathematical model for the simulation developed as a part of this research, a case study was developed to administer in a graduate level lean course. Pre- and post-case study surveys were also created to obtain the reviews of the students and faculty regarding the simulation.

As the simulation is used as an education tool, the case study was designed to evaluate its application as a learning method. Prince and Felder (2006) summarised the definitions, foundations, similarities, and differences among inductive learning methods. The authors also describe the case-based teaching method and compare it with other teaching methods. Yadav et al. (2007) conducted a survey to investigate the effects of using case studies in science courses and capture the views of the faculty on the benefits and challenges of using case studies. Yadav et al. (2010) also investigate the effects of the use of case studies in mechanical engineering courses. This information led to our development of a case study to validate our simulation platform as an educational tool.

\subsection{Case study development}

Prince and Felder (2006) reviewed inductive methods of teaching and concluded that the inductive methods of imparting knowledge are very powerful. They defined and explained the case-based instruction technique as an inductive method of imparting knowledge. These findings suggest that cases involving single or multiple challenges invoking students' abilities to diagnose technical problems, strategise for the selection of appropriate solutions, and make executive decisions are beneficial for students' active learning. The following case was developed using these principles.

The students were presented with a case study containing four processes of a hypothetical automotive axle manufacturing line. Figure 9 shows the layout for these processes. Further, the students were provided with the engineering drawings for the hypothetical part to be manufactured (Figure 10). Finally, the case study prompted the students to apply various lean tools through multiple questions at the end of the case.

Figure 9 Current layout

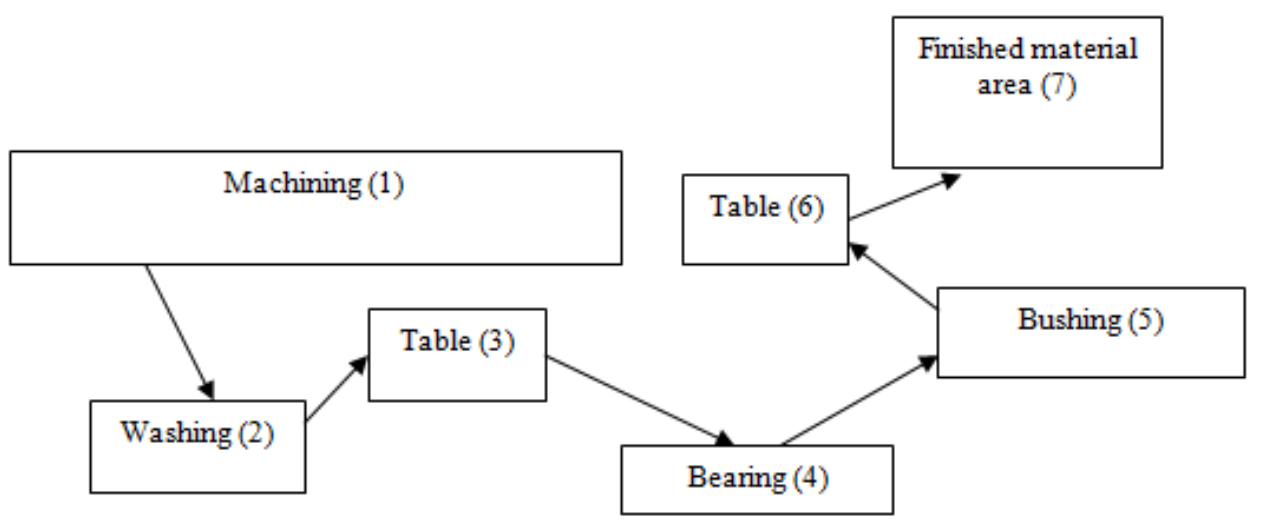


Figure 10 3D model of the workpiece (see online version for colours)

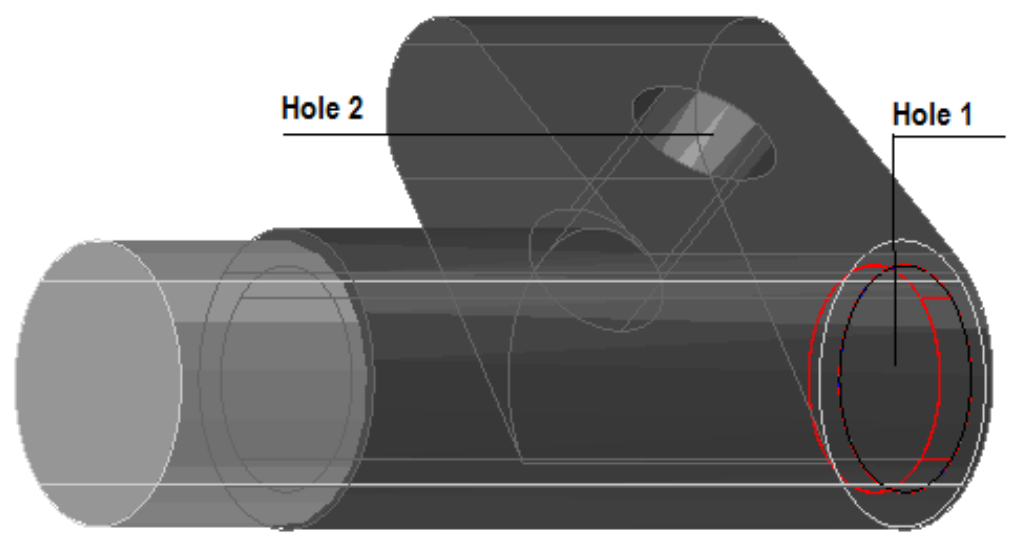

The first question prompts the students to construct the current state value stream map. VSM is the first step towards implementation of a lean improvement project. VSM displays the existing process clearly and helps students to visualise the locations and instances of wastes in the current production process (Rivera and Chen, 2007). The second question prompts the students to modify the layout to minimise the movement of WIP and operators. The students are expected to use cellular layout concepts for the layout modification. Cellular manufacturing results in motion waste reduction (Pavnaskar et al., 2003).

The third question sets a hypothetical demand and prompts the students to improve the process to meet the demand. In this question the students are prompted to calculate the takt time and compare it with the total process time, then improve the process in order to reduce the total process time and the takt time (Monroe, 2009; Shah and Ward, 2007). The third question also suggests creating flow by reducing the batch size.

Figure $113 \mathrm{D}$ model of the fixture

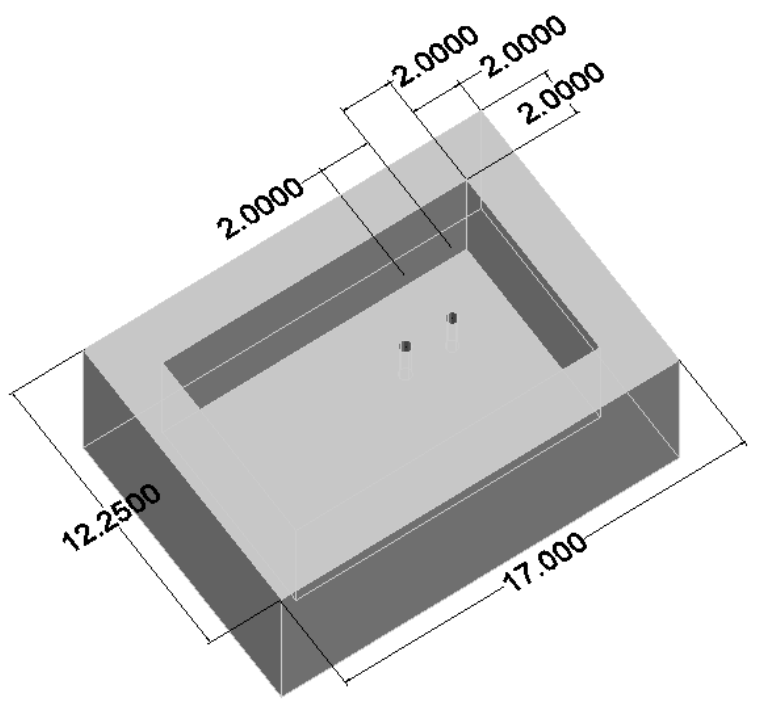


Figure 12 3D model of the fixture module

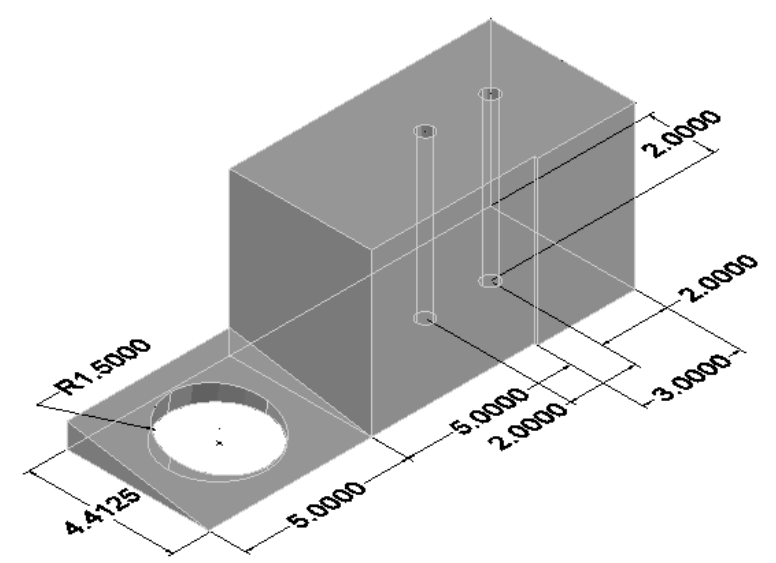

Question four increases the demand even further and prompts the student to calculate the required staffing level and change the total process time according to the new staffing level (Monroe, 2009). The fifth question prompts the use of SMED by increasing the demand even further, presents a sample fixture for the part (Figures 11 and 12), and asks for improvements to the fixture using SMED and standardised work principles. Finally, the sixth question asks the student to setup a kanban system using equation (8) (Mukhopadhyay and Shanker, 2005). While attempting these questions the students are not allowed to increase the usage of resources. By periodically increasing the customer demand the case study asks the students to improve the process. This gives the students an overview of customer centred continuous process improvements.

\subsection{Survey}

An initial survey was administered to capture the views of the students and the recommendations of the faculty. The recommendations and suggestions will be used to improve the mathematical model and virtual model. The following paragraphs explain the development of the surveys and the information the authors wished to capture through the surveys. The initial survey was based on the research of Yadav et al. (2010).

The survey aimed to measure the effects of including the case study in the lean course, capture the views of students and faculty, and collect data regarding the difficulties faced by the students and areas of improvement. The survey included specific questions to analyse the effect of the case study on the motivation, understanding, retention, critical thinking, and participation of the students. Twelve engineering management and systems engineering graduate students were given basic instruction on lean methods including use of the virtual simulation and then asked seven questions regarding how well the tool added to their understanding of those lean methods, with eight students providing responses. The available responses to the questions were strongly agree, agree, neutral, disagree, and strongly disagree. The questions and the results are given in Table 1. 
Table 1 Student responses to survey questions

\begin{tabular}{|c|c|c|c|c|c|}
\hline & $\begin{array}{l}\text { Strongly } \\
\text { agree }\end{array}$ & Agree & Neutral & Disagree & $\begin{array}{l}\text { Strongly } \\
\text { disagree }\end{array}$ \\
\hline $\begin{array}{l}\text { I felt the use of the virtual model } \\
\text { was relevant in learning about } \\
\text { the course concepts }\end{array}$ & 2 & 6 & & & \\
\hline $\begin{array}{l}\text { The virtual model helped me } \\
\text { synthesise ideas and information } \\
\text { presented in the course }\end{array}$ & 3 & 5 & & & \\
\hline $\begin{array}{l}\text { I thought the use of the virtual } \\
\text { model in the short course was } \\
\text { thought provoking }\end{array}$ & 2 & 3 & 3 & & \\
\hline $\begin{array}{l}\text { The virtual model allowed me to view } \\
\text { an issue from multiple perspectives }\end{array}$ & & 5 & 3 & & \\
\hline $\begin{array}{l}\text { The virtual model allowed } \\
\text { for a deeper understanding } \\
\text { of course concepts }\end{array}$ & 2 & 4 & & 2 & \\
\hline $\begin{array}{l}\text { The virtual model brought together } \\
\text { material I had learned in several } \\
\text { other engineering courses }\end{array}$ & & 2 & 6 & & \\
\hline $\begin{array}{l}\text { The virtual model added a lot of } \\
\text { realism to the short course }\end{array}$ & & 7 & 1 & & \\
\hline
\end{tabular}

Note: No entry designates zero responses of that type.

The results of the questions show that the students agreed that the virtual model was relevant to learning the course concepts and synthesising the material presented in the course. Most of the students thought the virtual model was thought provoking and allowed them to view the problem from multiple perspectives, with two responding neutrally. The students were mostly neutral ( $75 \%$ neutral and $25 \%$ agree) when asked if the virtual model brought together material learned from other engineering courses, and the majority of the students $(87.5 \%)$ said the virtual model added realism to the course. Some of the students did not think that the virtual model allowed for a deeper understanding of the material (25\%), although the majority did think it did (75\%).

\section{Conclusions and future work}

This research describes the creation of the mathematical model, development of various assignments, 3D models, layout, and code for the simulation in VE-Suite. The model uses prime laws of engineering such as Little's Law, OEE, and takt time. In addition, the developed assignments call for the usage of lean tools such as pull system, JIT, single piece flow, standard work, takt time, SMED, kaizen, kanban, and U-layout. This method leads to more student engagement and provides a low-cost active learning environment. The authors are currently working on the implementation of a case study into the model. This case study models a real-world production line for an automotive shaft with four processes.

The virtual simulation tool can be used as a virtual laboratory for courses that would benefit from a 'hands-on' approach such as the shop floor example given here. This 
should be added to a broader lean education curriculum to provide an active learning component to teaching lean tools. The students would be able to perform experiments and immediately see the suggested changes in the production line. The students would also be able to calculate the time and money saved by process improvement changes. This enables the model to help students learn through hands-on work, improve retention, and learn from mistakes, which could be costly if made in reality. The students in the preliminary testing of the virtual simulation found that the virtual model was beneficial to learning lean methods, with the majority of students reporting positive learning outcomes for all but one question, which received a neutral response. As the current assignments are centred on a mechanical assembly problem, this neutral response as to whether it brought together concepts from multiple courses may be expected. Additional assignments using more multi-disciplinary problems may make the tool better suited to broader engineering concepts.

Currently, the simulation model focuses on only those lean tools that require mathematical calculations. The methods proposed here for virtual lean engineering must be part of a larger curriculum that speaks to the management aspects of lean such as employee involvement, the need for top management support, and the methods to transition into lean manufacturing. To introduce the philosophical aspects of lean, the involvement of subject matter experts is necessary to provide this information and properly frame the tools shown here. This may be introduced as dialog or video that appears within the simulation to convey the theory behind the lean principles being applied if the virtual simulation is not being used in a conventional classroom environment led by these experts. In addition, other tools should be developed to aid the simulation for designing better course work for lean and related courses.

\section{References}

Aumann, C. (2007) 'A methodology for developing simulation models of complex systems', Ecological Modeling, Vol. 202, Nos. 3-4, pp.385-396.

Bagchi, S. and Ritzo, C. (2008) 'A full-factory simulator as a daily decision-support tool for $300 \mathrm{~mm}$ wafer fabrication productivity', Proceedings of the 2008 Winter Simulation Conference, pp.2021-2029.

Braglia, M., Frosolini, M. and Zammori, F. (2009) 'Overall equipment effectiveness of a manufacturing line (OEEML) an integrated approach to assess systems performance', Journal of Manufacturing Technology Management, Vol. 20, No. 1, pp.8-29.

Choi, B., Park, B. and Ryu, H. (2004) 'Virtual factory simulator framework for line prototyping', Journal of Advanced Manufacturing Systems, Vol. 3, No. 1, pp.5-20.

Cudney, E. and Elrod, C. (2011) 'A comparative analysis of integrating lean concepts into supply chain management in manufacturing and service industries', International Journal of Lean Six Sigma, Vol. 2, No. 1, pp.5-22.

Cudney, E., Corns, S., Grasman, S., Gent, S. and Farris, J. (2011) 'Enhancing undergraduate engineering education of lean methods using simulation learning modules within a virtual environment', Proceedings of the 2011 ASEE Annual Conference \& Exposition.

Deif, A. (2010) 'Computer simulation to manage lean manufacturing systems', 2nd International Conference on Computer Engineering and Technology, Vol. 6, pp.677-681.

Dengiz, B. and Akbay, K. (2000) 'Computer simulation of a PCB production line: meta-modeling approach’, International Journal of Production Economics, Vol. 63, No. 2, pp.195-205. 
Dessouky, M., Verma, S., Bailey, D. and Rickel, J. (2001) 'A methodology for developing a web-based factory simulator for manufacturing education', IIE Transactions, Vol. 33, No. 3, pp.167-180.

Dodd, D.A. (2008) 'Innovations in the classroom: algebra loses a bit of its gravity', The Atlanta Journal-Constitution, December 7, p.D1.

Kande, A. and Corns, S. (2011) 'Applying virtual engineering to model-based systems engineering', Systems Research Forum, Vol. 5, No. 2, World Scientific Publishing Company.

Klier, T. (1993) 'Lean manufacturing: understanding a new manufacturing system', Chicago Field Letter, March, Vol. 67, pp.1-4, ABI/INFORM Global.

Lee, J., Han, S. and Yang, J. (2011) 'Construction of a computer-simulated mixed reality environment for virtual factory layout planning', Computers in Industry, Vol. 62, No. 1, pp.86-98.

Leye, S., Himmelspach, J. and Uhrmacher, A. (2009) 'A discussion on experimental model validation', 11th International Conference on Computer Modeling and Simulation, pp.161-167.

Liker, J. (2004) The Toyota Way: 14 Management Principles from the World's Greatest Manufacturer, McGraw-Hill, New York, New York.

Little, J. and Graves, S. (2008) Building Intuition: Insights from Basic Operations Management Models and Principles, Chhajed, D. and Lowe, T.J. (Eds.), pp.81-100.

Madan, M., Son, Y., Cho, H. and Kulvatunyou, B. (2005) 'Determination of efficient simulation model fidelity for flexible manufacturing systems', International Journal of Computer Integrated Manufacturing, Vol. 18, Nos. 2-3, pp.236-250.

McCorkle, D.S. and Bryden, K.M. (2008) 'Virtual engineering and design of power systems', in Amano, R.S. and Sunden, B. (Eds.): Thermal Engineering in Power Systems, Chapter 3, WIT Press, Do Computational Mechanics Inc., 25 Bridge St., Billerica, MA 01821.

Monroe, D. (2009) 'Crunch time', Industrial Engineer, Vol. 41, No. 7, pp.44-47.

Moris, M., Ng, A. and Svensson, J. (2008) 'Simplification and aggregation strategies applied for factory analysis in conceptual phase using simulation', Proceedings of the 2008 Winter Simulation Conference, Vol. 6, pp.1913-1921.

Mukhopadhyay, S. and Shanker, S. (2005) 'Kanban implementation at a tyre manufacturing plant: a case study', Production Planning \& Control, Vol. 16, No. 5, pp.488-499.

National Academy of Engineering (2005) Educating the Engineer of 2020: Adapting Engineering Education to the New Century, The National Academic Press, Washington, DC.

Ni, Y., Li, J., He, W. and Yao, J. (2011) 'An systematic modeling and simulation study on WIP optimization in semiconductor assembly and test factory', Advanced Materials Research, pp.201-203, 1086-1092.

Nicholas, J. and Soni, A. (2006) 'The portal to lean production: principles and practices for doing more with less', Auerbach Publications, p.57, Boca Raton, FL.

Pavnaskar, S., Gershenson, J. and Jambekar, A. (2003) 'Classification scheme for lean manufacturing tools', International Journal of Production Research, Vol. 41, No. 13, pp.3075-3090.

Prince, M. and Felder, R. (2006) 'Inductive teaching and learning methods: definitions, comparisons, and research bases', Journal of Engineering Education, Vol. 95, No. 2, pp.123-138.

Reyes, J., Eldridge, S., Barber, K. and Meier, H. (2010) 'Overall equipment effectiveness (OEE) and process capability (PC) measures: a relationship analysis', International Journal of Quality \& Reliability Management, Vol. 27, No. 1, pp.48-62.

Rezg, N., Xie, X. and Mati, Y. (2004) 'Joint optimization of preventive maintenance and inventory control in a production line using simulation', International Journal of Production Research, Vol. 42, No. 10, pp.2029-2046. 
Rivera, F. and Chen, F. (2007) 'Measuring the impact of lean tools on the cost-time investment of a product using cost-time profiles', Robotics and Computer Integrated Manufacturing, Vol. 23, No. 6, pp.684-689.

Sanders, J. and Udoka, S. (2010) 'An information provision framework for performance-based interactive elearning application for manufacturing', Simulation Gaming, Vol. 41, No. 4, pp.511-536.

Shah, R. and Ward, P. (2007) 'Defining and developing measures of lean production', Journal of Operations Management, Vol. 25, No. 4, pp.785-805.

Tobail, A., Crowe, J. and Arisha, A. (2012) 'Serious gaming learning: supply chain multi-agent web-based simulation game', Fifth International Conference of Education, Research and Innovation.

Vickovic, L., Celar, S. and Mudnic, E. (2011) 'Disk array simulation model development', International Journal of Simulation and Modeling, Vol. 10, No. 1, pp.27-37.

Wall, J. and Ahmed, V. (2008) 'Use of a simulation game in delivering blended lifelong learning in the construction industry - opportunities and challenges', Computers \& Education, Vol. 50, No. 4, pp.1383-1393.

Wan, H., Chen, F. and Saygin, C. (2008) 'Simulation and training for lean implementation using web-based technology', International Journal of Services Operations and Informatics, Vol. 3 , No. 1, pp.1-14.

Wang, P., Mohamed, Y., Abourizk, S., Asce, S. and Rawa, A. (2009) 'Flow production of pipe spool fabrication: simulation to support implementation of lean technique', Journal of Construction Engineering and Management, October, pp.1027-1038.

Yadav, A., Lundeberg, M., DeSchryver, M., Dirkin, K., Schiller, N., Maier, K. and Herreid, C. (2007) 'Teaching science with case studies: a national survey of faculty perceptions of the benefits and challenges of using cases', The Journal of College Science Teaching, Vol. 37, No. 1, pp.34-39.

Yadav, A., Shaver, G. and Meckl, P. (2010) 'Lessons learned: implementing the case teaching method in a mechanical engineering course', Journal of Engineering Education, Vol. 99, No. 1, pp.55-64.

Yang, T., Zhang, D., Chen, B. and Li, S. (2008) 'Research on simulation and evaluation of production running in digital factory environment', International Symposium on Computer Science and Computational Technology, pp.547-550. 